\title{
Culturalismo e Universalismo diante do Estado Plurinacional
}

José Luiz Quadros de Magalháes

ceede@uol.com.br

Professor do programa de pós-graduação em Direito da PUC-Minas e Unipac.

Professor da Universidade

Federal de Minas Gerais

Recebimento do artigo: 16/02/2010

Aprovado em: 12/08/2010

\section{Resumo}

O artigo trata da questão do chamado infanticídio indígena diante das teorias universalistas e culturalistas. No texto, o autor procura uma alternativa à radicalidade das duas teorias, buscando elementos de reflexão no Estado plurinacional. A ideia de um Estado plurinacional representa uma novidade capaz de romper com a lógica moderna de Estado vigente há 500

anos. Trata-se de um Estado efetivamente diverso, fundado na multiplicidade de ordenamentos jurídicos e na criação de um espaço dialógico igual para a construção de uma agenda mínima de direitos humanos.

\section{Palavras-chave}

Plurinacionalidade. Comunidades originárias. Infanticídio. Direitos humanos. 


\title{
Culturalism and Universalism before the Plurinational State
}

\author{
José Luiz Quadros de Magalbáes
}

Abstract

The present essay deals with the question of indigenous infanticide in face of the universalistic and relativist theories. The author intends to search for an alternative to the radicalism of both theories by finding elements of reflection in the plurinational State. The plurinational State consists of an idea capable of breaking the logic of the modern State, in existence for over 500 years. The plurinational State is a diverse entity, founded amidst a multiplicity of legal orders, providing an equal dialogic space for the construction of a minimum agenda of human rights.

Key words

Plurinationality. Native communities. Infanticide. Human rights. 


\section{Sumário}

Introdução.

I O Estado nacional.

II O Estado plurinacional.

III Como o Estado plurinacional pode representar novas soluções democráticas para as questões da diversidade cultural frente à bioética.

IV Criar espaços de discussão sem superioridades: essa é a proposta do Estado plurinacional.

Conclusões.

Bibliografia.

\section{Introdução}

As novas constituições da Bolívia e Equador do ano de 2009 são uma grande novidade para o direito constitucional, ao representar uma potencial ruptura com o paradigma do estado nacional e sua uniformização de valores, típica desse paradigma moderno.

Além de uma novidade para o constitucionalismo e ,logo, para o direito, a proposição teórica do Estado plurinacional pode representar, também, um novo paradigma para a construção de uma nova ordem jurídico-institucional internacional. $\mathrm{O}$ Estado nacional, construído na realidade europeia a partir do século XV, procura uniformizar o direito de família e de propriedade, criando assim as condições do exercício de um poder centralizado e hierarquizado.

Neste texto propomos uma nova construção jurídica, que rompa com a hegemonia européia que começa chegar ao fim. Para isto procuramos conhecer o Estado plurinacional como um modelo de ordem jurídica plural, diversa, democrática e tolerante, que seja capaz de criar espaços de diálogo permanente, onde as partes envolvidas possam comparecer em condições de igualdade de fala, sem se submeterem a pseudo-imperativos valorativos, construídos por qualquer cultura 
e, dessa forma, possam efetivamente estabelecer uma agenda mundial de direitos capazes de ser universalizados.

Outra novidade da proposta é o fato de que ela não se enquadra nas tradicionais visões culturalistas ou universalistas. De um lado, uma visão culturalista não servirá para encobrir violações de direitos e autoritarismo, uma vez que esses grupos se comprometem a discutir permanentemente. Sentar-se a uma mesa (de forma simbólica) e discutir tudo é a melhor forma de superar intolerâncias e violências. Enquanto houver debate, não haverá violência. Sem dúvida essa estratégia é muito mais eficaz do que intervenções armadas com supostas razões humanitárias, todas sempre muito trágicas. Neste ponto podemos dizer que um direito que efetivamente deve ser universalizado é existência de espaços permanentes de discussão.

De outro lado, afastamos um discurso, que nos soa hipócrita, de um universalismo que nunca foi universal, mas europeu. A imposição de valores e direitos se mostrou como uma forma eficaz de dominação e imposição dos interesses de potências hegemônicas quase sempre europeias, mesmo que não se encontrassem no continente europeu. Mesmo as mais legítimas intervenções humanitárias encobrem ou encobriram outros interesses hegemônicos.

Para demonstrarmos o potencial da ideia do Estado plurinacional na construção de alternativas aos importantes debates bioéticos vamos, neste texto, explicar primeiramente a formação do estado nacional, entender seu significado e importância para então compreendermos as bases do estado plurinacional. Finalmente estudaremos um caso concreto que envolva uma questão bioética, procurando compreender como o novo paradigma plurinacional pode apresentar soluções democráticas para a questão. E ser importante para o respeito aos direitos humanos democraticamente construídos.

\section{O Estado Nacional}

A formação do Estado moderno a partir do século XV ocorre após lutas internas em que o poder do rei se afirma perante os senhores feudais, unificando o poder interno, os exércitos e a economia, para então afirmar este mesmo poder perante os poderes externos, os impérios e a Igreja. Trata-se de uma força unificadora numa esfera intermediária, pois cria, de um lado um poder organizado e hierarquizado internamente, sobre os conflitos regionais, as identidades existentes anteriormente à formação do reino e do estado nacional, que surge nesse momento e, de outro lado, afirma-se perante o poder da Igreja e dos Impérios. Esse é o processo que ocorre em Portugal, Espanha, França e Inglaterra. ${ }^{1}$

CREVELD, Martin van Creveld. Ascensão e declínio do Estado. São Paulo: Editora Martins 
Desses fatos históricos decorre o surgimento do conceito de soberania em duplo sentido: a soberania interna, organizada a partir da unificação do reino sobre os grupos de poder representados pelos nobres (senhores feudais), com a adoção de um único exército, subordinado a uma única vontade; a soberania externa, extruturada a partir da não submissão automática à vontade do papa e ao poder imperial (multi-étnico e descentralizado).

Um problema importante surge neste momento, fundamental para o reconhecimento do poder do Estado, pelos súditos inicialmente, mas que permanece para os cidadãos no futuro estado constitucional: para que o poder do rei (ou do Estado) seja reconhecido, esse rei não pode se identificar particularmente com nenhum grupo étnico interno. Os diversos grupos de identificação pré-existentes ao Estado nacional não podem criar conflitos ou barreiras intransponíveis de comunicação, pois ameaçarão a continuidade do reconhecimento do poder e do território desse novo Estado soberano. Assim a construção de uma identidade nacional se torna fundamental para o exercício do poder soberano.

Dessa forma, se o rei pertence a uma região do Estado, que tem uma cultura própria, valores com os quais ele claramente se identifica, dificilmente um outro grupo, com outras identificações, reconhecerá o seu poder. Assim, a tarefa principal desse novo Estado é criar uma nacionalidade (conjunto de valores de identidade) que seja acima das identidades (ou podemos falar mesmo em nacionalidades) pré-existentes. ${ }^{2}$ A unidade da Espanha ainda hoje está, entre outras razões, na subordinada ao poder do Estado em manter uma nacionalidade espanhola sobre as nacionalidades pré-existentes (galegos, bascos, catalães, andaluzes, castelhanos, entre outros). O dia em que essas identidades regionais prevalecerem sobre a identidade espanhola, o Estado espanhol estará condenado à dissolução. Como exemplo recente, podemos citar a fragmentação da Iugoslávia entre vários pequenos estados independentes (estados étnicos) como a Macedônia, Sérvia, Croácia, Montenegro, Bósnia, Eslovênia e, em 2008, o impasse com Kosovo. Portanto, a tarefa de construção do

Fontes. 2004 e CUEVA, Mario de la. La idea del Estado, Fondo de Cultura Econômica, Universidad Autônoma de México, Quinta Edição, México, D.F., 1996.

2 Utilizamos neste texto as palavras identidade e identificações quase como sinônimos, ou seja, uma identidade se constrói a partir da identificação de um grupo com determinados valores. Importante lembrar que o sentido dessas palavras é múltiplo em autores diferente em criticas. Podemos adotar o sentido de identidade como um conjunto de características que uma pessoa tem e que permitem múltiplas identificações, sendo dinâmicas e mutáveis. Já a idéia de identificação se refere ao conjunto de valores, características e práticas culturais com as quais um grupo social se identifica. Nesse sentido não poderíamos falar em uma identidade nacional ou uma identidade constitucional mas sim em identificações que permitem a coesão de um grupo. Identificação com um sistema de valores ou com um sistema de direitos e valores que o sustentam, por exemplo. 
Estado nacional (do Estado moderno) dependia da construção de uma identidade nacional ou, em outras palavras, da imposição de valores comuns que deveriam ser compartilhados pelos diversos grupos étnicos, pelos diversos grupos sociais para que assim todos reconhecessem o poder do Estado, do soberano. Assim, na Espanha, o rei castelhano agora era espanhol, e todos os grupos internos também deveriam se sentir espanhóis, reconhecendo assim a autoridade do soberano.

Esse processo de criação de uma nacionalidade dependia da imposição e aceitação pelos cidadãos, de valores comuns. Quais foram inicialmente esses valores? Um inimigo comum (na Espanha do século XV os mouros, o império estrangeiro), uma luta comum, um projeto comum e, naquele momento, o fator fundamental unificador: uma religião comum. Assim a Espanha nasceu com a expulsão dos muçulmanos e, posteriormente, dos judeus. Foi criada na época uma polícia da nacionalidade: a santa inquisição. Ser espanhol era ser católico, e quem não se comportasse como um bom católico era excluído.

A formação do Estado moderno esteve, portanto, intimamente relacionado com a intolerância religiosa, cultural, a negação da diversidade fora de determinados padrões e limites. O Estado moderno nasceu da intolerância com o diferente, e dependeu de políticas de intolerância para sua afirmação. Até hoje assistimos ao fundamental papel da religião nos conflitos internacionais, a intolerância com o diferente. Mesmo Estados que constitucionalmente aceitam a condição de estados laicos têm na religião uma base forte de seu poder: o caso mais assustador é o dos Estados Unidos, divididos entre evangélicos fundamentalistas de um lado e protestantes liberais de outro. Isso repercute diretamente na política do Estado, nas relações internacionais e nas eleições internas. A mesma vinculação religiosa com a política dos Estados podemos perceber em uma União Européia cristã, que resiste à aceitação da Turquia e convive com o crescimento da população muçulmana europeia.

O Estado moderno foi a grande criação da modernidade, somada mais tarde, no século XVIII, com a afirmação do Estado constitucional.

$\mathrm{Na}$ América Latina, os Estados nacionais se formam a partir das lutas pela independência no decorrer do século XIX. Um fator comum nesses Estados é o fato de que, quase invariavelmente, foram Estados construídos para uma parcela minoritária da população, não interessando para as elites econômicas e militares, que a maior parte da população se sentisse integrante, se sentisse parte do Estado. Dessa forma, em proporções diferentes em toda a América, milhões de povos originários (de grupos indígenas os mais distintos) assim como milhões de imigrantes forçados, africanos, foram radicalmente excluídos de qualquer ideia de nacionalidade. $\mathrm{O}$ direito não era para essas maiorias, a nacionalidade não era para essas pessoas. Não 
interessava às elites que indígenas e africanos se sentissem nacionais.

De forma diferente da Europa, onde foram construídos Estados nacionais para todos que se enquadrassem no comportamento religioso imposto pelo poder central, na América não se esperava que os indígenas e negros se comportassem como iguais seria melhor que permanecessem à margem, ou mesmo, no caso dos povos originários (chamados indígenas pelo invasor europeu), que não existissem: milhões foram mortos.

Nesse sentido, as revoluções da Bolívia e do Equador, seus poderes constituintes democráticos, fundam um novo Estado, capaz de superar a brutalidade dos estados nacionais nas Américas: o Estado plurinacional, democrático e popular.

Nunca, na América, tivemos tantos governos democráticos populares como neste surpreendente século XXI. O importante é que esses governos não são apenas democráticos representativos, mas fortemente participativos, dialógicos.

Uma idéia nova, nesse processo, chama a atenção: o Estado plurinacional das Constituições do Equador e da Bolívia.

\section{O Estado Plurinacional}

A América Latina vem sofrendo um processo de transformação social-democrática importante e surpreendente. Da Argentina ao México, os movimentos sociais vêm se mobilizando e conquistando importantes vitórias eleitorais. Direitos historicamente negados aos povos originários da terra chamada "América" pelo invasor europeu agora são reconhecidos. Em meio a esses variados processos de transformação social, percebemos que cada país, diante de suas peculiaridades históricas, vem trilhando caminhos diferentes, mas nenhum abandonou o caminho institucional da democracia representativa, somando a esta uma forte democracia dialógica participativa.

Assim, em 2009, assistimos ao Uruguai de Tabaré Vasquez buscar a reconstrução dos direitos sociais; a Argentina de Cristina Kirchner reformar as forças armadas, introduzindo o ensino dos Direitos Humanos; o Paraguai de Lugo na busca do resgate de uma divida centenária de humilhação e exclusão dos pobres e dos povos originários; o Chile de Michelle Bachelet tentando quebrar a resistência de uma classe média conservadora e machista; a Venezuela de Hugo Chaves caminhando para o socialismo; o povo de El Salvador elegendo um governo comprometido com os direitos democráticos e sociais; e especialmente a Bolívia e o Equador, onde governos eleitos com o forte apoio popular promulgaram suas novas Constituições e, com estas, um conceito totalmente inovador para o mundo jurídico: o Estado Revista Mestrado em Direito, Osasco, ano 10, n. 2, p. 201-219 
plurinacional.

Vamos apenas introduzir esse conceito como fruto de um processo democrático que se iniciou com revoluções pacíficas, em que os povos originários (chamados pelo invasor de indígenas), finalmente, após 500 anos de exclusão radical, reconquistaram gradualmente sua liberdade e dignidade.

A ideia de Estado plurinacional pode superar as bases uniformizadoras e intolerantes do Estado nacional, em que todos os grupos sociais devem se conformar aos valores determinados na constituição nacional em termos de direito de família, direito de propriedade e sistema econômico entre outros aspectos importantes da vida social. Como vimos anteriormente, o Estado nacional nasce a partir da uniformização de valores com a intolerância religiosa.

A partir da constitucionalização e sua lenta democratização (em geral, ainda de bases liberais meramente representativas), não se poderia mais admitir a construção da identidade nacional manter com base em uma única religião que uniformizasse o comportamento no plano econômico (direito de propriedade) e no plano familiar. Tornou-se necessário construir uma outra justificativa e um outro fator agregador que permitisse aos diversos grupos sociais presentes no Estado moderno reconhecerem-se e, a partir daí, reconhecer o poder do Estado como legítimo.

A Constituição irá cumprir essa função. Inicialmente não democrático, o constitucionalismo irá uniformizar (junto com o direito civil) as bases valorativas dessa sociedade nacional, criando um único direito de família e um único regime de propriedade que sustentaria o sistema econômico. Isto ocorreu em qualquer dos tipos constitucionais: liberal; social ou socialista.

A uniformização de valores e comportamentos, especialmente na família e na forma de propriedade, exclui radicalmente grupos sociais (étnicos e culturais) distintos que, ou se enquadram ou são jogados, aos milhões, para fora dessa sociedade constitucionalizada (uniformizada). O destino desses povos é a alienação, o aculturamento e perda de raízes ou então a miséria, os presídios ou ainda os manicômios.

A lógica do Estado nacional agora constitucionalizado e mesmo "democratizado" sustenta essa uniformização. A ideologia que justifica tudo isso é a existência de um suposto "pacto social" ou "contrato social”, ou qualquer outra idéia que procure identificar, nas bases dessas sociedades americanas, um suposto acordo uniformizador, como se as populações originárias tivessem abdicado de sua história e cultura para assumir o direito de família e o direito de propriedade do invasor europeu, que continuou no poder com seus descendentes brancos a partir dos processos de independência no século XIX. A grande revolução do Estado plurinacional é o fato de que esse Estado constitucional, democrático, participativo e dialógico pode final- 
mente romper com as bases teóricas e sociais do Estado nacional, constitucional e democrático representativo (pouco democrático e nada representativo dos grupos não uniformizados), uniformizador de valores e, logo, radicalmente excludente. $\mathrm{O}$ Estado plurinacional reconhece a democracia participativa como base da democracia representativa e garante a existência de formas de constituição da família e da economia segundo os valores tradicionais dos diversos grupos sociais (étnicos e culturais) existentes.

Nas palavras de Ileana Almeida ${ }^{3}$ sobre o processo de construção do Estado plurinacional no Equador: "Sin embargo, no se toma en cuenta que los grupos étnicos no luchan simplemente por parcelas de tierras cultivables, sino por un derecho histórico. Por lo mismo se defienden las tierras comunales y se trata de preservar las zonas de significado ecológico-cultural."

Certamente esse Estado joga por terra o projeto uniformizador do Estado moderno, que sustenta a sociedade capitalista como sistema único, fundado na falsa naturalização da família e da propriedade e mais tarde da economia liberal. Nas palavras de Ileana Almeida:

Al funcionar el Estado como representación de uma nacion única
cumple también su papel en el plano ideológico. La privación de dere-
chos políticos a las nacionalidades no hispanizadas lleva al desconoci-
miento de la existência misma de otros pueblos y convierte al indígena
em vitima del racismo. La ideología de la discriminación, aunque no
es oficial, de hecho está generalizada en los diferentes estratos étnicos.
Esto empuja a muchos indígenas a abandonar su identidad y pasar a
forma filas de la nación ecuatoriana aunque, pó lo general, en su sec-
tores más explotados. ${ }^{4}$

A Constituição da Bolívia, na mesma linha de criação de um Estado plurinacional, dispõe sobre a questão indígena em cerca de 80 dos 411 artigos. Pelo texto, os 36 "povos originários" (aqueles que viviam na Bolívia antes da invasão dos europeus) passam a ter participação ampla, efetiva em todos os níveis do poder estatal e na economia. Com a aprovação da nova Constituição, a Bolívia passou a ter uma cota para parlamentares oriundos dos povos indígenas, que também passarão a ter propriedade exclusiva sobre os recursos florestais e direitos sobre a terra e os recursos hídricos de suas comunidades. A Constituição estabelece a equivalência entre a justiça tradicional indígena e a justiça ordinária do país. Cada comunidade indígena poderá ter seu próprio "tribunal”, com juízes eleitos entre os moradores. As deci-

\footnotetext{
3 ALMEIDA, Ileana. El Estado Plurinacional - valor histórico e libertad política para los indígenas ecuatorianos. Editora Abya Yala, Quito, Ecuador, 2008, pág.21.

4 ALMEIDA, Ileana. El Estado Plurinacional - valor histórico e libertad política para los indígenas ecuatorianos. Editora Abya Yala, Quito, Ecuador, 2008., pág.19. 20
} 
sões desses tribunais não poderão ser revisadas pela Justiça comum.

Outro aspecto importante é a descentralização das normas eleitorais. Assim, os representantes dos povos indígenas poderão ser eleitos a partir das normas eleitorais de suas comunidades. A Constituição ainda prevê a criação de um Tribunal Constitucional plurinacional, com membros eleitos pelo sistema ordinário e pelo sistema indígena. A nova Constituição democrática transforma a organização territorial do país. O novo texto prevê a divisão em quatro níveis de autonomia: o departamental (equivalente aos Estados brasileiros), o regional, o municipal e o indígena. Pelo projeto, cada uma dessas regiões autônomas poderá promover eleições diretas de seus governantes e administrar seus recursos econômicos. O projeto constitucional avança ainda na construção do Estado plurinacional, ao acabar com a vinculação do estado com a religião (a religião católica ainda era oficial) transformando a Bolívia em um Estado laico (o que o Brasil é desde 1891).

Outro aspecto importante é o reconhecimento de várias formas de constituição da família.

Além de importante instrumento de transformação social, garantia de direitos democráticos, sociais, econômicos plurais e pessoais diversos, a Constituição da Bolívia é um modelo de construção de uma nova ordem política, econômica e social internacional. É o caminho para se pensar em um Estado democrático e social de direito internacional.

Citando novamente Ileana Almeida:

En contra de los que podría pensarse, el reconocimiento de la especi-
ficidad étinica no fracciona la unidad de las fuerzas democráticas que
se alinean en contra del imperialismo. Todo lo contrario, mientras más
se robustezca la conciencia nacional de los diferentes grupos, más fir-
me será la resitencia al imperialismo bajo cualquiera de sus formas
(genocídio, imposición política, religiosa o cultural) y, sobre todo, la
explotación econômica. ${ }^{5}$

A América Latina (melhor: agora, a América Plural), que nasce renovada nestas democracias dialógicas populares, se redescobre também indígena, democrática, economicamente igualitária e social (mente) e culturalmente diversa, plural. Em meio à crise econômica e ambiental do globo, que anuncia o fim de uma época de violências, fundada no egoísmo e na competição, a nossa América anuncia finalmente algo de novo, democrático e tolerante, capaz de romper com a intolerância unificadora e violenta de quinhentos anos de Estado nacional.

ALMEIDA, Ileana. El Estado plurinacional - valor histórico e libertad política para los indígenas ecuatorianos. Editora Abya Yala, Quito, Ecuador, 2008., pág.19.-20 


\section{Como o Estado Plurinacional pode representar novas soluções democráticas para as questões da diversidade cultural frente à bioética}

A ordem europeia uniformizadora (uma era de 500 anos) parece estar chegando ao fim. Logo, não podemos pensar um "Estado democrático e social de direito", que seja capaz de enfrentar as novas complexidades trazidas pelos avanços tecnológicos frente à diversidade cultural e busca da democracia dialógica efetiva, fundado nos mesmos paradigmas hegemônicos uniformizadores de sempre. Por esse motivo, propomos uma ordem constitucional efetivamente plural, igualitária e democrática, para a qual buscamos o modelo de Estado plurinacional previsto nas Constituições da Bolívia e Equador de 2009.

Esse Estado rompe com o paradigma de 500 anos de Estado nacional, permitindo que cada grupo étnico preserve seu próprio direito de família, e de propriedade e tribunais próprios para resolver os conflitos nesses âmbitos, criando um espaço de diálogo democrático onde as partes comparecem em condição de igualdade para construir uma agenda comum de Direitos Humanos (ou fundamentais na perspectiva constitucional).

Vamos a seguir estudar um complexo caso que envolve a questão da diversidade cultural e os direitos dos povos originários no Brasil, para aplicarmos a lógica da plurinacionalidade conforme proposta nas Constituições da Bolívia e do Equador neste caso real.

O Brasil tem mais de 220 etnias originárias (indígenas, para os europeus) com padrões diversos de idioma, história e cultura. Alguns desses grupos étnicos possuem, entre seus costumes, práticas que contrariam o pensamento hegemônico "internacional" a respeito dos direitos humanos consagrados na declaração de direitos da Constituição Federal brasileira. Entre essa prática, está o chamado "infanticídio indígena". Poucos países no mundo têm sido tão radicais na prática do não intervencionismo, tese defendida por antropólogos da ABA (Associação Brasileira de Antropologia) na FUNAI e algumas ONG’s. Dessa forma, o "infanticídio" tem sido prática em diversas comunidades de povos originários no Brasil, onde crianças "defeituosas" e gêmeas têm sido mortas.

A partir dessa realidade, foi proposto projeto de lei (PJ 1057/2007) que aponta como criminosas doze práticas consideradas "nocivas" à sociedade, presentes na cultura dos povos originários, incluindo essas práticas o infanticídio.

A Convenção da Organização Internacional do Trabalho N. 169 em seu artigo 8, n.2, dispõe que os indígenas podem ter seus costumes e tradições mantidos, segundo suas próprias instituições, desde que não contrariem os direitos fundamentais Revista Mestrado em Direito, Osasco, ano 10, n. 2, p. 201-219 
estabelecidos nacionalmente e os direitos humanos internacionais.

O Projeto de Lei (PL) 1057/2007 dispõe sobre o “combate a práticas tradicionais nocivas e à proteção dos direitos fundamentais de crianças indígenas, bem como pertencentes a outras sociedades ditas não tradicionais.”

$\mathrm{O}$ artigo $1^{\circ}$ do PL reafirma o respeito e o fomento a práticas tradicionais indígenas e de outras sociedades ditas não tradicionais, sempre que elas "estejam em conformidade com os direitos humanos fundamentais, estabelecidos na Constituição Federal e internacionalmente reconhecidos".

A seguir o PL estabelece no artigo $2^{\circ}$ as práticas tradicionais consideradas nocivas à vida e à integridade físico-psíquica:

I. homicídios de recém-nascidos, em casos de falta de um dos genitores;

II. homicídios de recém-nascidos, em casos de gestação múltipla;

III. homicídios de recém-nascidos, quando estes são portadores de deficiências físicas e/ou mentais;

IV. homicídios de recém-nascidos, quando há preferência de gênero;

V. homicídios de recém-nascidos, quando houver breve espaço de tempo entre uma gestação anterior e o nascimento em questão;

VI. homicídios de recém-nascidos, em casos de exceder o número de filhos considerado apropriado para o grupo;

VII. homicídios de recém-nascidos, quando estes possuírem algum sinal ou marca de nascença que os diferencie dos demais;

VIII. homicídios de recém-nascidos, quando estes são considerados portadores de má-sorte para a família ou para o grupo;

IX. Homicídios de crianças, em caso de crença de que a criança desnutrida é fruto de maldição, ou por qualquer outra crença que leve ao óbito intencional por desnutrição;

$\mathrm{X}$. Abuso sexual, em quaisquer condições e justificativas;

XI. Maus-tratos, quando se verificam problemas de desenvolvimento físico e/ou psíquico na criança.

XII. Todas as outras agressões à integridade físico-psíquica de crianças e seus genitores, em razão de quaisquer manifestações culturais e tradicionais, culposa ou dolosamente, que configurem violações aos direitos humanos reconhecidos pela legislação nacional e internacional.

No Artigo $3^{\circ}$, o PL dispõe que

qualquer pessoa que tenha conhecimento de casos em que haja suspeita ou confirmação de gravidez considerada de risco (tais como os itens mencionados no artigo $2^{\circ}$ ), de crianças correndo risco de morte, seja por envenenamento, soterramento, desnutrição, maus-tratos ou qualquer outra forma, deverá obrigatoriamente comunica-los, preferencialmente por escrito, por outras formas (rádio, fax, telex, telégrafo, correio eletrônico, entre outras) ou pessoalmente, à FUNASA, à FUNAI, ao Conselho Tutelar da respectiva localidade ou, na falta deste, à autoridade judiciária e policial, sem prejuízo de outras providências legais. 
Acrescenta ainda o art. $4^{\circ}$. que

é dever de todos que tenham conhecimento das situações de risco, em função de tradições nocivas, notificar imediatamente as autoridades acima mencionadas, sob pena de responsabilização por crime de omissão de socorro, em conformidade com a lei penal vigente, a qual estabelece, em caso de descumprimento

pena de detenção, de 1 (um) a 6 (seis) meses, ou multa.

$\mathrm{O}$ art. $5^{\circ}$ acrescenta que as autoridades descritas no art. $3^{\circ}$ respondem, igualmente, por crime de omissão de socorro, quando não adotem, de maneira imediata, as medidas cabíveis.

$\mathrm{O} \operatorname{art} .6^{\circ}$. dispõe que

constatada a disposição dos genitores ou do grupo em persistirem na prática tradicional nociva, é dever das autoridades judiciais competentes promover a retirada provisória da criança e/ou dos seus genitores do convívio do respectivo grupo e determinar a sua colocação em abrigos mantidos por entidades governamentais e não governamentais, devidamente registradas nos Conselhos Municipais dos Direitos da Criança e do Adolescente.

Acrescenta que é

dever das mesmas autoridades gestionar, no sentido de demovê-los, sempre por meio do diálogo, da persistência nas citadas práticas, até o esgotamento de todas as possibilidades ao seu alcance. O parágrafo único dispõe que, "frustradas as gestões acima, deverá a criança ser encaminhada às autoridades judiciárias competentes para fins de inclusão no programa de adoção, como medida de preservar seu direito fundamental à vida e à integridade físico-psíquica.

Finalmente o PL dispõe, no seu artigo $7^{\circ}$, que serão adotadas medidas para a erradicação das práticas tradicionais nocivas, sempre por meio da educação e do diálogo em direitos humanos, tanto em meio às sociedades em que existem tais práticas, como entre os agentes públicos e profissionais que atuam nessas sociedades. Os órgãos governamentais competentes poderão contar com o apoio da sociedade civil nesse intuito.

Vários problemas surgem a partir dessa norma que podem ser solucionados de forma inteligente, por meio da lógica da plurinacionalidade.

\section{Cultura é vida}

Durante 500 anos, desde o início do processo de invasão e colonização das "Américas" pelos europeus, a cultura destes, com pretensão de superioridade, foi imposta aos povos originários. A invasão, colonização e dominação ocorreram não 
só pela força das armas, mas por meio de uma imposição cultural onde a religião teve um papel fundamental. Assim, desde o início do processo, religiosos europeus, entre eles os dedicados jesuítas, passaram a evangelizar os chamados "indígenas" (povos originários).

Imagine o leitor que de repente aparecem seres "extraterrestres" que se mostram superiores, com tecnologia e armas mais sofisticadas. Estes "seres" descem de suas "embarcações flutuantes" e trazem objetos desconhecidos e idéias novas. Então eles nos revelam que tudo em que acreditamos, tudo que nossos pais, nossos ancestrais nos ensinaram não tem valor. Esses seres nos revelam que nosso Deus não existe, nossa crença é falsa, que Jesus Cristo não existiu, que os valores cristãos não são corretos e que nossa forma de viver não é boa. O que esses "seres" fizeram conosco? Retiraram nossas raízes, nossos referenciais de vida, nossas coordenadas. Sem essas coordenadas nos perdemos, enfraquecemos, enlouquecemos. Esses "seres" retiraram de nós nossa história, nossos ancestrais, nossas raízes que nos permitiam ficar de pé.

Isso os invasores europeus (os evangelizadores europeus) fizeram e ainda fazem com os povos originários. Esses povos, afastados de sua história, de suas crenças e valores, de seus pais e ancestrais, desenraizados, não conseguem se mater em pé. Muitos se suicidam, muitos encontram nas drogas e no álcool refúgio para o desespero.

\section{A destruição cultural mata as pessoas}

Vamos então analisar o artigo $7^{\circ}$, que mostra o espírito do projeto de lei acima referido. Esse dispositivo estabelece que

serão adotadas medidas para a erradicação das práticas tradicionais nocivas, sempre por meio da educação e do diálogo em direitos humanos, tanto em meio às sociedades em que existem tais práticas, como entre os agentes públicos e profissionais que atuam nestas sociedades. Os órgãos governamentais competentes poderão contar com o apoio da sociedade civil neste intuito.

É obvio, que a partir de nossos referenciais religiosos e culturais, condenamos a prática de infanticídio, mas não estaremos, de novo, para salvar vidas, matando-a de outra forma? Novamente, partindo de um pressuposto de superioridade da civilização europeia, não estaríamos ignorando nossos próprios problemas?

Repetimos 500 anos de história europeia retornando às tristes teses de Sepúlveda, que até hoje sustentam as intervenções humanitárias que matam mais do que o problema que visam resolver. Juan Ginés Sepúlveda (século XVI) escreveu sobre os "ameríndios": "bárbaros, simplórios, iletrados e não instruídos, brutos totalmente 
incapazes de aprender qualquer coisa que não seja atividade mecânica, cheios de vícios, cruéis e de tal tipo que se aconselha que sejam governados por outros." ${ }^{\circ}$

Interessante, nessa comparação, como naquela época e hoje, as atrocidades cometidas pelos civilizados não eram vistas como tais. A inquisição, a queima de pessoas em fogueiras, as torturas, a fome, a violência urbana e rural, a ganância, a propriedade privada e as guerras não eram coisas de bárbaros. $\mathrm{O}$ mesmo comportamento continua hoje. A fome, as favelas, a desnutrição, a ganância desmedida, a propriedade privada, a guerra, a criminalidade e a violência policial contra os pobres, inclusive crianças e adolescentes, a tortura sistemática nas cadeias e delegacias não incomoda os civilizados. Selvagens e iletrados são os outros.

Sepúlveda influencia claramente a política externa das potências ocidentais. Esse pensador europeu escreveu a sua segunda tese:

\begin{abstract}
os índios devem aceitar o jugo espanhol mesmo que não o queiram, como retificação (enmienda, emendentur) e punição por seus crimes contra a lei divina e natural com os quais estão manchados, principalmente a idolatria e o costume ímpio do sacrifício humano. ${ }^{7}$
\end{abstract}

\title{
Os "indios" em museus
}

A política alternativa, a intervenção civilizadora e a equivocada criminalização, invasão e imposição cultural tem sido a "museificação" dos povos originários no Brasil. Se a tentativa da solução do "problema" por meio do direito penal e a imposição de uma visão "civilizada" do mundo contra a barbárie ou selvageria "indígena” é equivocada, também não é correto colocar os povos originários em redomas de vidro para serem preservados como peças de museus longe do contato com a civilização. Essa visão talvez seja ainda mais preconceituosa do que a anterior, e continua a tratar os povos originários como inferiores, que não devem ter contato com a "civilização" pois podem ter sua "frágill" cultura contaminada ou destruída pela "forte" civilização. Essa visão é perversa, pois nega a história para esses povos, que se tornam peças de museus para antropólogos estudarem.

Esta tem sido a postura adotada no Brasil em diversos momentos. Sob o argumento de proteção dessas culturas (vista como frágeis e ,que por isso, precisam ser mantidas no museu da história) negam o diálogo e a possibilidade de esses povos serem agentes de sua história e mais de se integrarem em condição de igualdade para a construção de um mundo plural, onde para o qual, poderiam contribuir fortemente sugerindo de agendas comuns.

Não é essa a visão do "Estado plurinacional".

6 WALLERNSTEIN, Immanuel. O universalismo europeu. São Paulo: Boitempo, 2007, p. 32.
7 WALLERNSTEIN, Immanuel. O universalismo europeu. São Paulo: Boitempo, 2007, p. 34.

Revista Mestrado em Direito, Osasco, ano 10, n. 2, p. 201-219 


\section{Criar espaços de discussão igual sem superioridades: essa é a proposta do Estado plurinacional}

Qual a diferença da proposta do estado plurinacional na Bolívia e Equador? A fundamental diferença é o fato de que, nesse estado, até mesmo por serem majoritários, os povos originários assumiram a sua própria história. E sem excluir aqueles que os excluíram durante 500 anos, passaram a construir um "Estado" que, de forma diferente do estado nacional, formado pelos invasores europeus e seus descendentes, tem espaço para todos em efetiva diversidade.

A questão acima estudada, do infanticídio em algumas culturas originárias, pode ser colocada dentro de uma nova perspectiva, uma nova equação.

Assim como o Estado plurinacional pode servir de uma alternativa entre culturalismo e universalismo, a lógica da plurinacionalidade pode servir de alternativa entre o intervencionismo "civilizador" de um lado e a "museificação" preconceituosa de outro lado.

A criação de espaços institucionalizados e permanentes de diálogos entre os diversos grupos sociais, étnicos, culturais, presentes em um espaço territorial determinado (que, em ultima instancia, finalmente pode ser todo o globo mas pode começar nos estados) deve colocar, em condição de igualdade de fala, todos esses grupos.

Esse novo arranjo de poder nos estados deve partir do reconhecimento de múltiplos ordenamentos jurídicos e da construção de um ordenamento constitucional comum, dialogicamente estruturado em torno de uma agenda mínima, constantemente revista e ampliada, de direitos fundamentais.

Assim, cada comunidade local (não necessariamente étnica) poderá construir ou preservar seu próprio direito de família assim como seu próprio direito de propriedade com tribunais locais para resolver as questões nesses âmbitos. No mesmo momento, a construção de espaços institucionais "plurinacionais" deve garantir que esses diversos grupos sociais (étnicos ou não) possam dialogar permanentemente em condição de igualdade (sem presunções de superioridade civilizacional, étnica ou qualquer outra pretensão) para a constituição de uma agenda histórica e dinâmica de direitos humanos.

Assim, pode ser que um dia concordemos em não mais matar as pessoas em sistemas econômicos egoístas; na ganância da sociedade de consumo; nas guerras; nos conflitos urbanos. Pode ser resolvamos não matar mais as crianças de fome ou em qualquer outra forma de infanticídio. 


\section{Conclusões}

Para para que se compreenda a grande contribuição do Estado plurinacional e do constitucionalismo boliviano e equatoriano para a construção de um novo paradigma democrático de Estado que supere os 500 anos de Estado nacional, precisamos pontuar algumas questões:

1. Vimos que o estado moderno surge a partir da afirmação de uma esfera territorial intermediária de poder: os reis entre o poder dos impérios (multi-étnico e descentralizado) e o poder dos senhores feudais (local e fragmentado);

2. Para que o poder desse novo Estado fosse reconhecido, foi necessário construir uma nacionalidade sobre as nacionalidades pré-existentes. Assim foi inventado o espanhol como uma identidade acima as identidades anteriores de castelhanos, galegos, bascos, catalães e outros, processo que se repetiu em escalas diferentes na França, Portugal, Reino Unido e vários outros Estados nacionais que se formaram nos últimos quinhentos anos;

3. Esse estado nacional uniformiza valores por meio, inicialmente, da religião. A partir daí e gradualmente, será construído todo um aparato burocrático que permitirá o desenvolvimento do capitalismo: o povo nacional, a moeda nacional, os bancos nacionais, os exércitos nacionais (fundamental para a expansão europeia à busca de recursos para o desenvolvimento de sua economia) e a polícia (fundamental para o controle e repressão dos pobres excluídos do sistema econômico desigual);

4. Desde então, esse modelo uniformizador vem se reproduzindo, até mesmo nas novas formas descentralizadas de Estado como os Estados federais, os Estados regionais e o estado autonômico espanhol. Nesses Estados, mesmo reconhecendo a diversidade cultural, lingüística, a base uniformizadora do direito de propriedade (que sustenta um sistema econômico único) e o direito de família (que sustenta os valores deste sistema econômico) permanecem mais ou menos intactas, mas sólidos;

5. A uniformização econômica fundada na uniformização do direito de família e do direito de propriedade permanece também em novas formas jurídicas como, por exemplo, o direito comunitário europeu;

6. Nas Américas, os Estados nacionais tiveram um processo de formação diferenciado: enquanto na Europa os mais diferentes foram excluídos fisicamente (muçulmanos e judeus) e os menos diferentes foram uniformizados (os grupos étnicos internos), na América, os estados formados, que se tornaram independentes nos séculos XVIII e XIX, foram construídos pelos descendentes dos europeus para os homens brancos, descendentes dos europeus. Os povos originários, chamados de 
índios pelos perdidos invasores europeus, foram radicalmente excluídos da ordem jurídica constitucional nascente, assim como os imigrantes forçados da África que tiveram suas vidas escravizadas;

7. Assim surgiram, nas Américas, estados nacionais para 20\% (este é um número simbólico uma vez que encontramos estados em que até hoje a exclusão supera esse número). Nos Estados Unidos, a população carcerária já atinge 2.750 .000 pessoas (dois milhões, setecentos e cinquenta mil pessoas) sendo que desses, $80 \%$ são negros e hispânicos. Só de homens negros, são 800 mil presos, e mulheres negras, 75 mil presas. Esse fenômeno se repete em toda a América. No Brasil, só os pobre são presos. A maioria dos povos originários na Bolívia, Equador e Chile foram radicalmente excluídos e só agora, com governos democráticos, finalmente eleitos (Evo Morales na Bolívia; Rafael Correa no Equador e Michelle Bachelet no Chile) a situação começa a mudar;

8. A onda democrática na América Latina trouxe uma importante novidade: a previsão de um Estado plurinacional, onde cada grupo étnico poderáconservar o seu próprio direito de família e o seu próprio direito de propriedade, mantendo ainda tribunais para resolver as questões nestas esferas;

9. Essa novidade pode finalmente representar uma ruptura com 500 anos de hegemonia do paradigma do Estado nacional, que representa a hegemonia europeia;

O Estado plurinacional representa uma nova perspectiva democrática de construção permanente de conteúdos de direitos. A superação de uma perspectiva hegemônica cultural dos direitos humanos, representada pelo chamado "universalismo europeu", abre espaço para a convivência de diversas perspectivas de mundo; para a convivência entre percepções diversas de família e de economia. Essa proposta, presente nos textos constitucionais da Bolívia e Equador de 2009, e em gradual processo de organização histórica, pretende superar a construção ideológica da superioridade cultural europeia diante do mundo e, logo, de sua superioridade moral e jurídica. No lugar de direitos humanos impostos por culturas com pretensão de superioridade, o Estado de direito plurinacional propõe a construção de uma agenda mínima de direitos humanos, que possa ser permanentemente rediscutida e ampliada, construída de forma democrática e, portando, sem hegemonias.

Trata-se de um novo universalismo, um universalismo sem violências, sem hegemonias, onde o permanente diálogo entre culturas e percepções de mundo possa permitir o surgimento de um universalismo verdadeiramente universal, com permanentes construções e reconstruções de consensos históricos em torno dos direitos humanos. 


\section{Bibliografia}

ALMEIDA, Ileana. E1 Estado plurinacional - valor histórico e libertad política para los indígenas ecuatorianos. Quito, Ecuador: Abya Yala, 2008.

CREVELD, Martin van. Ascensão e declínio do Estado. São Paulo: Martins Fontes, 2004.

CUEVA, Mario de la. La idea del Estado. 5. ed. México DF: Fondo de Cultura Económica, Universidad Autónoma de México, 1996.

WACQUANT, Loïc. As duas faces do gueto. São Paulo: Boitempo, 2008.

WALLERNSTEIN, Immanuel. O universalismo europeu. São Paulo: Boitempo, 2007. 